\title{
MEDIA PROMOSI DAN INFORMASI GUNA PENUNJANG IKLAN SPORT PARTY (GOFIT) PT. ARKA MAHESA PRATAMA JAKARTA
}

\author{
M. Ifran Sanni ${ }^{l}$ \\ Siti Maesaroh ${ }^{2}$ \\ Rifqi Baihaqi ${ }^{3}$ \\ Dosen AMIK Raharja Informatika ${ }^{1}$, Dosen STMIK Raharja ${ }^{2}$, STMIK Raharja Jurusan Teknik \\ Informatika ${ }^{3}$ \\ Jl. Jendral Sudirman No. 40, Modern Cikokol, Tangerang \\ Email : ifran@ raharja.info ${ }^{1)}$, siti.maesaroh@ raharja.info $^{2)}$, rifqi.baihaqi@raharja.info $^{3)}$
}

\begin{abstract}
ABSTRAK
PT. Arka Mahesa Pratama Jakarta pada saat ini masih menggunakan media desain atau acara event hingga website tetapi hasil dari media tersebut masih kurang efektif sehingga banyak masyakat belum mengetahiunya. PT. Arka Mahesa Pratama Jakarta sangat membutuhkan projek berbentuk media video iklan agar masyarakat lebih mengtahui. Pada konsep tersebut terdapat tahapan preproduction, production dan postproduction. Untuk mendapatkan hasil projek yang maksimal maka membutuhkan penunjang aplikasi yang akan digunakan sehingga hasil akhir karya projek video lebih menarik.
\end{abstract}

Kata Kunci : media, desain, informasi.

\section{ABSTRACT}

PT. Arka Mahesa Pratama Jakarta at the moment still use media design or events to websites but the result of such media are still less effective so many masyakat yet mengetahiunya. PT. Arka Mahesa Pratama Jakarta desperately needs the project shaped media video ads so the public know more. On the concept of there stages of preproduction, production and postproduction. To get the maximum project then the need of supporting applications that will be used so that the end result of the work of the project video more interesting.

Keywords: media, design, information.

\section{PENDAHULUAN}

Dalam perkembangannya, iklan sering ditemui di media cetak maupun elektronik, seperti iklan majalah, iklan koran, iklan TV, ataupun iklan radio. Dari beberapa jenis iklan tersebut yang paling mudah dipahami adalah iklan dalam bentuk visual. Dengan adanya suara dan video maka orang dapat dengan cepat dan mudah memahami maksud dari iklan tersebut.

\section{RUMUSAN MASALAH}

PT. Arka Mahesa Pratamamasih belum memiliki iklan sehingga PT. Arka Mahesa Pratama ber keinginan membuat video iklan agar banyak di lihat dan dapat di ketahui oleh masyarakat.

\section{LANDASAN TEORI Pengertian Media}


Menurut Roya Choupani. (2014-21) Penyimpanan pesan atau salah satu komunikasi periklanan yang dilakukan media tertentu, seperti televisi, surat kabar, majalah, radio, internet, buku profil, media luar ruangan, iklan transit dan direct mail.

\section{Pengertian Informasi}

Danny Agniawan, dkk. (2017-32). Data menjadi suatu bentuk yang penting atau yang dapat di rasakan dalam keputusan - keputusan yang akan datang.

\section{Pengertian Promosi}

Memperkenalkan produk dengan memikat hati melalui pemberian kesan - kesan baik.

\section{Pengertian Animasi}

Objek (gambar) yang di susun beraturan mengikuti pergerakan setiap pertambahan hitungan waktu yang terjadi.

\section{Pengertian Animasi 2D}

Atanasov. (2015-51) Animasi menggunakan komputer (software) kemampuan menggambar lembar demi lembar animasi.

\section{Pengertian Periklanan}

Media untuk memberitahukan konsumen tentang mengajak mereka melakukan sesuatu.

\section{Tujuan Multimedia}

Christian Laura,. (2015-76) kombinasi dari beragam bentuk konten seperti teks, audio, video, gambar dan animasi untuk memberikan informasi atau hiburan kepada pengguna.

\section{Tahapan Produksi Audio Visual}

\section{Pra Produksi}

menetapkan sebuah skenario yang disepakati bersama sebagai draf skenario akhir; pembedahan skenario (scenario breakdown); pembuatan papan produksi (production strip board); pembuatan jadwal; membuat perkiraan anggaran; memanggil kru (recruitment); pencarian lokasi; perijinan; pencarian pemain (casting); tanda tangan kontrak kerja; latihan; dan pembuatan call sheet (jadwal shooting).

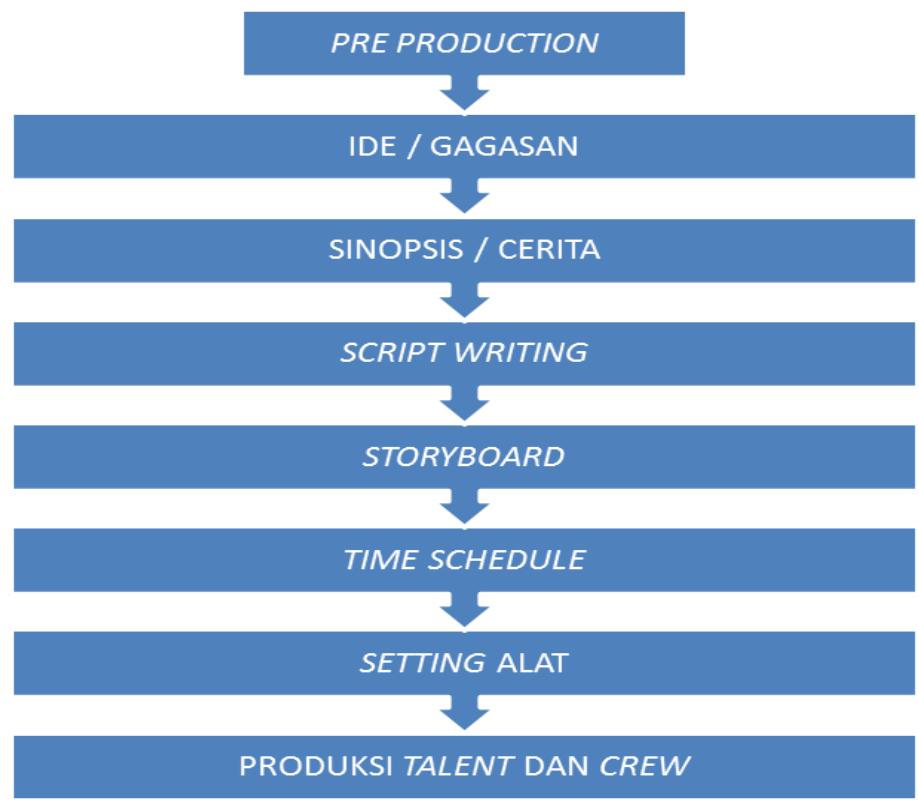

Gambar 1. Tahapan Pra Produksi 


\section{Produksi}

"memproduksi program doku-drama agak mirip dengan memproduksi program dokumenter. Namun dalam doku-drama adegan yang terjadi di masa lalu bisa direkayasa."

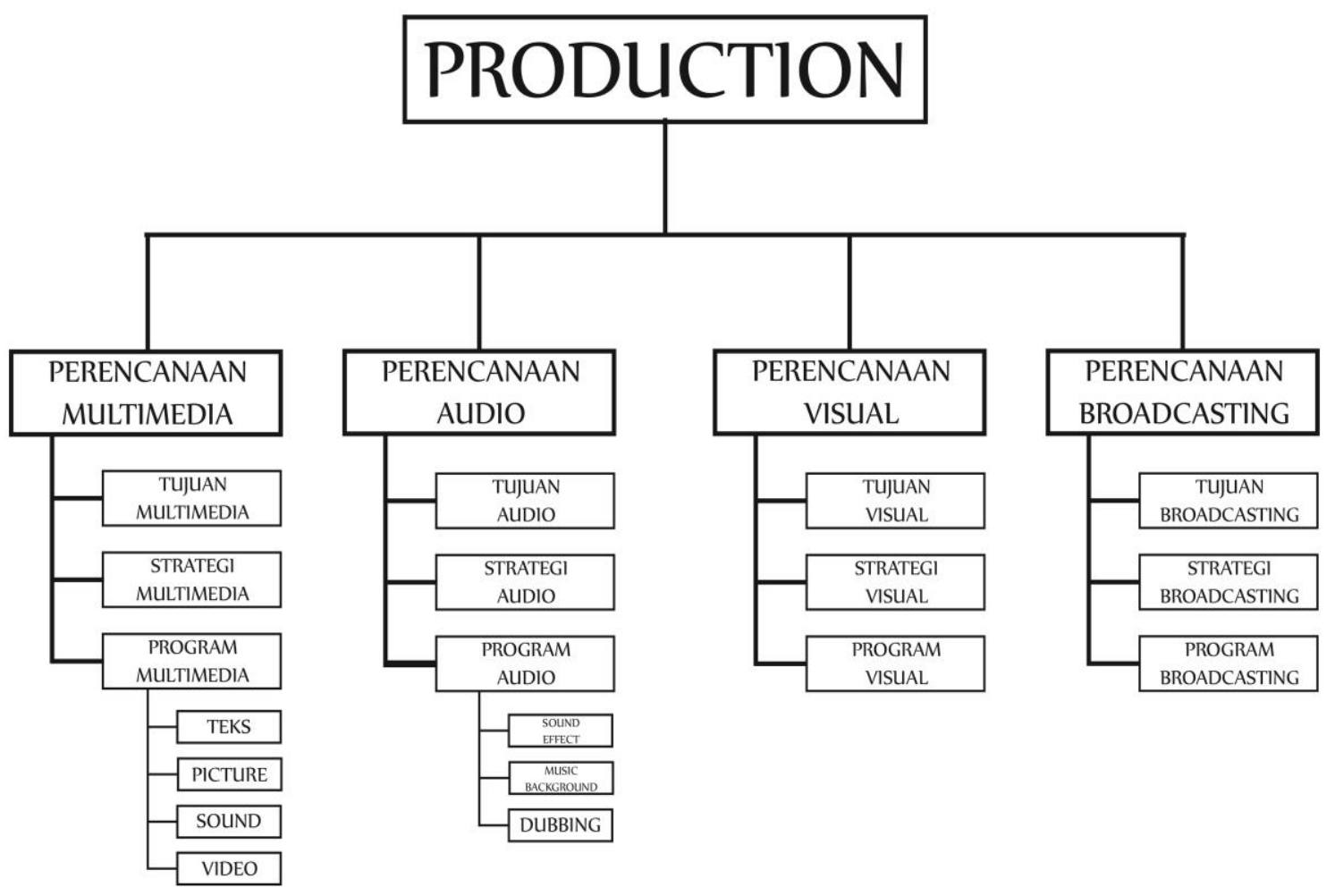

\section{Post Produksi}

Gambar 2. Tahapan Produksi

"Pascaproduksi (penyuntingan) peliputan/shooting/taping sehingga materi selesai disiarkan atau diputar kembali.

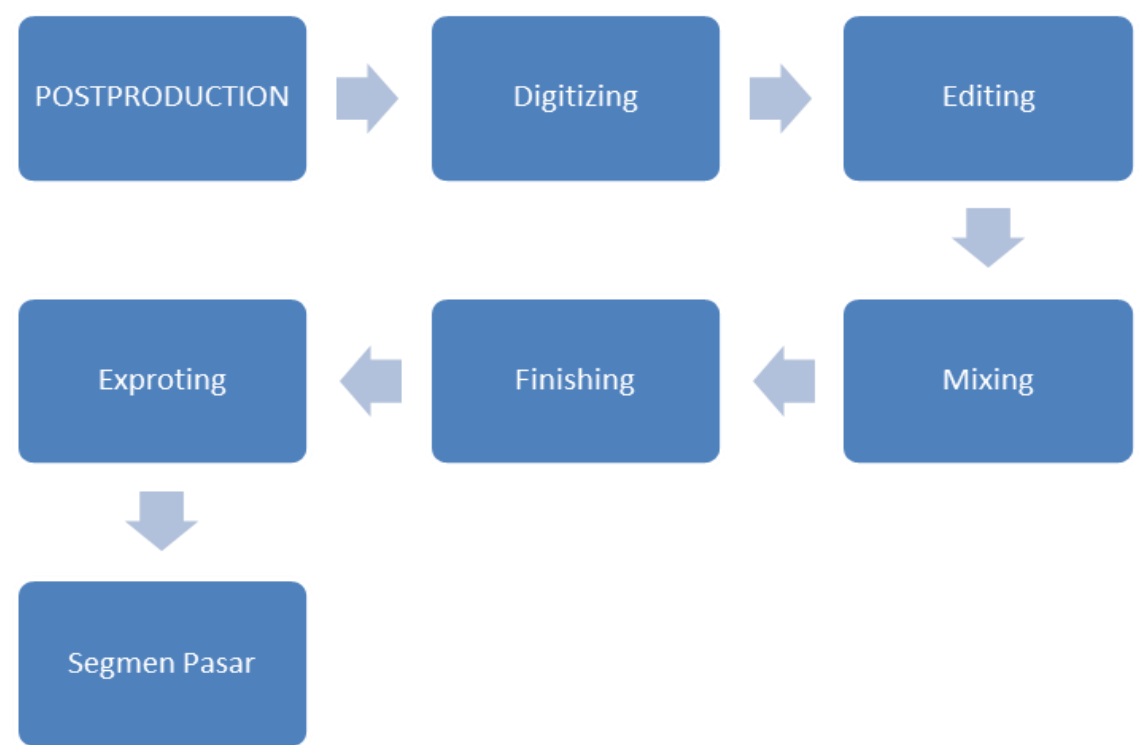

Gambar 3. Pasca Produksi 


\section{Storyboard}

Scene 1

Menampilkan video
Animasi Gofit Project dan
Grandkemang

Gambar 4. Menampilkan video Animasi Gofit Project dan Grandkemang

Scene 2

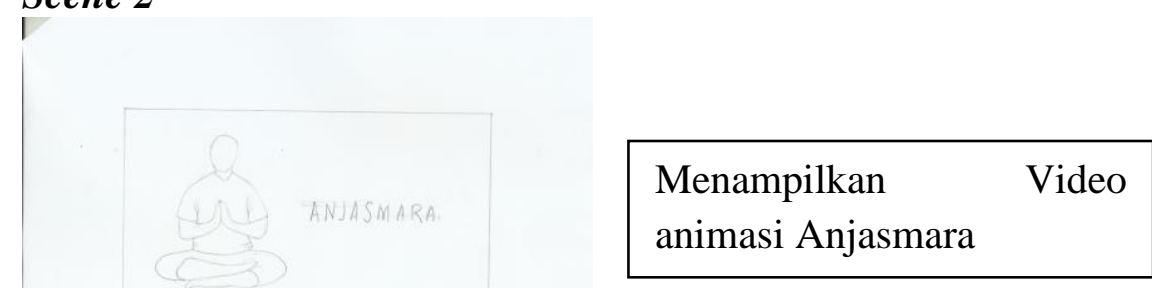

Gambar 5. Menampilkan Video animasi Anjasmara

\section{Scene 3}

$\begin{array}{ll}\text { Menampilkan } & \text { Video } \\ \text { Animasi junko dan } & \text { fabio } \\ \text { team } & \end{array}$

Gambar 6. Menampilkan Video Animasi junko dan fabio team

\section{Scene 4}

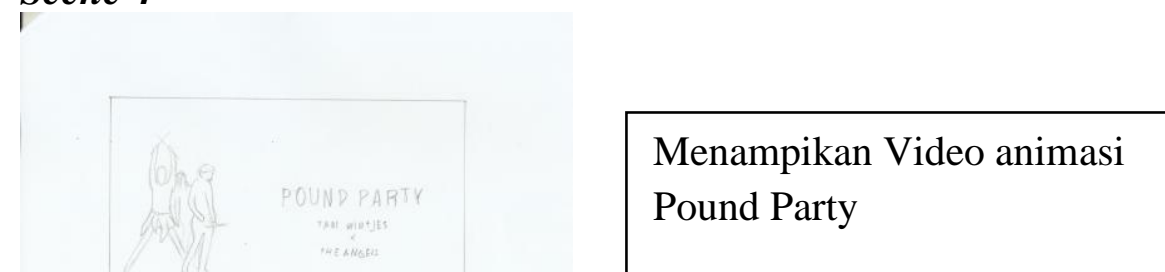

Gambar 7: Menampikan Video animasi Pound Party 
Scane 5

Menampilkan Video

Animasi Annisa Munaf

Gambar 8. Menampilkan Video Animasi Annisa Munaf

Scane 6

Menampilkan Berbagai

Macam Kelas Yang Tersedia

Gambar 9. Menampilkan Berbagai Macam Kelas Yang Tersedia

Scane 7

Menampilkan Video

Animasi hari dan tanggal

acara di grandkemang

Gambar 10. Menampilkan Video Animasi hari dan tanggal acara di grandkemang

\section{Scane 8}

Menampilkan Video tulisan

Animasi MNC vision.

Gambar 11. Menampilkan Video tulisan Animasi MNC vision.

Adobe After Effect CC

Animasi video berbasis bitmap yang biasa di gunakan di dunia televisi dan perfilman.

\section{Adobe Illustrator CC}

program pengolah grafis vector yang di gunakan untuk membuat berbagai macam desain. Adobe Illustrator di kembangkan oleh Adobe Inc pada tahun 1986. 
Sebenarnya tanpa adobe media encoder melakukan export dan rendering sebuah project video, tidak selengkap adobe media encoder, terutama bagian format atau codec pada video.

\section{LITERATUR REVIEW}

1. Penelitian yang di lakukan oleh ria dan Fitri (2017) "Rancangan Video Media Promosi Berbasis Motion Graphic 2D Untuk Meningkatkan Jumlah Mahasiswa Universitas Widyagama Malang”. Kebutuhan terhadap media promosi di suatu instansi menjadi sebuah kebutuhan utama. Karena media promosi sangat mempengaruhi keberlangsungan sistem pada suatu instansi. Universitas Widyagama merupakan salah satu kampus terkemuka di kota Malang, tapi menurut penulis dinilai masih belum lebih di kenal di banding Perguruan Tinggi Negeri (PTN) lainnya. Dengan perkembangan jaman dan semakin canggihnya teknologi, media promosi audio visual yang tepat utnuk memrpomosikannya ialah melalui animasi. Penulis memilih media animasi $2 D$ jenis SFA (Short Form Animation) untuk merancang media promosi pada Universitas Widyagama Malang. Dengan SFA diharapkan, dapat menyajikan informasi yang akurat, tepat, dan efektif. Karena jika informasi di sajikan terlalu lama, dapat mengurangi minat target promosi.

2. Penelitian yang di tulis Muhammad Algiffari (2015) ${ }^{[3]}$ "Perancangan Motion Graphic (Bumper In) dan Video Dokumenter Permainan Tradisional Jawa Bart (Analisis Deskriptif Permainan Tradisional Pada Sanggar Seni Tikukur Majalengka)". Permainan tradisional ialah salah satu kebudayaan lokal yang memiliki manfaat bagi perkembangan seorang anak. Tapi perkembangan zaman telah lebih modern sehingga masyarakat perlahan meninggalkan kebudayaan tradisional lalu lebih memilih budaya baru karena adanya proses akulturasi dan asimilasi. Media untuk dokumentasi tentang permainan tradisional pun masih terbilang kurang. Dan media yang paling efektif mendokumentasikannya ialah video karena memiliki unsur visual dan audio yang mudah dipahami bagi yang menontonnya. Jenis video yang dapat digunakan untuk mendokumentasikan permainan tradisional, salah satunya dalah video dokumenter. Dan video dokumenter tidak terlepas dari perancangan bumper in, sehingga dalam menampilkan bumper di awal berupa animasi motion graphic. Peneliti mencoba membuat media informasi berupa video dokumenter dengan menggabungkan motion graphic sebagai bumper in, sehingga media informasi ini dapat menjadi pengetahuan bagi masyarakat sebagai usaha untuk melestarikan permainan tradisional.

3. Penelitian yang di tulis Danny Agniawan dkk (2017) ${ }^{[2]}$ berjudul "Media Informasi Prosedur Tugas Akhir Mahasiswa FKTI Universitas Mulawarman Berbasis Animasi Motion Graphic (Studi Kasus : PT. Satnetcom Balikpapan)”. Di dalam sebuah perguruan tinggi, dalam akhir menempuh pendidikannya, mahasiswa dihadapkan pada tugas akhir skripsi. Dalam pengerjaan tugas akhir, terdapat tahapan dan syarat yang harus di kerjakan mahasiswa untuk menyelesaikan tugas akhir. Tahapan dan syarat tugas akhir skripsi terangkum dalam prosedur tugas akhir mahasiswa yang dibuat untuk memperjelas alur tugas. Maka dari itu penulis berinisiatif membuat informasi tambahan yang menarik yaitu berinovasi dalam menyajikan standar operasional prosedur tugas akhir mahasiswa FKTI Universitas Mulawarman dalam bentuk video animasi berbasis animasi motion graphic, untuk menunjang pengetahuan mahasiswa mengenai prosedur pengerjaan tugas akhir. 
4. Penelitian oleh Dini dan Yasermi (2017) ${ }^{[16]}$ berjudul "Motion Graphic Masjid Agung Palembang Sebagai Media Promosi Pariwisata Kota Palembang". Peninggalan masa lalu yang memiliki eksistensi yang terekam keberadaannya sampai sekarang ialah warisan budaya. Sejarah panjang dalam keanekaragaman warisan budaya berupa bangunan bersejarah yang tersebar di seluruh daerah di Indonesia. Salah satu daerah yang memiliki bangunan bersejarah yaitu kota Palembang. Dan bangunan yang memiliki sejarahnya ialah Masjid Agung Palembang, Untuk mempromosikan pariwisata Kota Palembang yakni melalui teknologi bidang komputer desain yaitu motion graphic. Peneliti membuat penelitian ini dalam upaya meningkatkan kunjungan wisatawan ke Masjid Agung Palembang yang merupakan salah satu bangunan bersejarah.

5. Penelitian oleh Dian dan Tumimomor (2017) ${ }^{[10]}$ berjudul "Perancangan Media Sosialisasi Tanggap Bencana Kabupaten Semarang Berbasis Animasi 2D”. Indonesia adalah wilayah yang rawan terjadi bencana, yang disebabkan alam atau perilaku manusia itu sendiri dan kabupaten Semarang salah satunya, pada awal tahun 2016 saja sudah terjadi 24 bencana. Dan untuk memberikan pengertian pada tanggap bencana kepada masyarakat, BPBD Kabupaten Semarang telah melakukan beberapa usaha sosialisasi ke berbagai desa maupun lembaga Pendidikan, dalam bentuk lisan, buku, maupun poster, namun medianya masih kurang variatif sehingga diperlukan media informasi lain tanggap bencana kepada masyarakat dengan lebih menarik dan informatif. Dan media yang di tampilkan bisa dalam berbagai bentuk, salah satunya media audio visual yakni video. Dan yang di pilih ialah video motion graphic. Sehingga diharapkan video motion graphic tersebut memberikan informasi lebih kepada masyarakat perhal tanggap bencana sehingga mengurangi kerugian serta dampak yang ada dari bencana.

\section{KESIMPULAN}

Cara untuk membuat suatu jasa atau barang lebih bisa membuat masyarakat tertarik atau timbul saya ingin tahu dan kemudian ingin membeli jasa atau produk. Bisa berupa Audio atau Video. Program iklan layanan mayarakat telah melalui beberapa tahapan, sehingga dapat terselesaikan sesuai dengan prosedur yang ada. Setiap tahapan dilaksanakan semaksimal mungkin karena iklan layanan masyarakat merupakan sebuah media yang menuntut kecermatan dan ketepatan dalam penyampaian pesan dan pengemasannya

\section{DAFTAR PUSTAKA}

[1] Agniawan, Danny, Joan Ngelina W. dan Edy Budiman. 2017. Media Informasi Prosedur Tugas Akhir Mahasiswa FKTI Universitas Mulawarman Berbasis Animasi Motion Graphic (Studi Kasus : PT. Satnetcom Balikpapan). Prosiding Seminar Nasional Ilmu Komputer Dan Teknologi Informasi Vol. 2 No. 2. Samarinda : Universitas Mulawarman.

[2] Algiffari, Muhammad. 2015. Perancangan Motion Graphic (Bumper In) dan Video Dokumenter Permainan Tradisional Jawa Barat (Analisis Deskriptif Permainan 
Tradisional Pada Sanggar Seni Tikukur Majalengka). Jurnal Sketsa Vol. 2 No. 1. Bandung : Universitas BSI Bandung.

[3] Anita, Ria Diajeng dan Fitri Marisa. 2017. Rancangan Video Media Promosi Berbasis Motion Graphic 2D Untuk Meningkatkan Jumlah Mahasiswa Universitas Widyagama Malang. Journal Of Information Technology And Computer Science (JOINTECS) Vol. 1 No. 2. Malang : Universitas Widyagama Malang.

[4] Atanasov, Ivaylo and Pencheva, Evelina. 2015. Model Aspects of Open Access to Multimedia Broadcast Services in the Evolved Packet System, Bulgaria : Technical University of Sofia, 8 Kliment Ohridski Boulevard

[5] Choupani, Roya. 2014. Spatial Multiple Description Coding for Scalable Video Stream, Turkey : Elektrik-Elektronik Mühendisligi Bölümü, Mühendislik Fakültesi, Aksaray Üniversitesi, 68100 Aksaray

[6] Desrianti, Dewi Immaniar Dan Sudaryono, Dan Dwi Ayu Ningrum. 2014. Enriching Media Merchandise Sarana Penunjang Promosi Studi Kasus Pada Bookstore. Journal CCIT Vol. 7 No. 3. Tangerang : Perguruan Tinggi Raharja.

[7] Laura, Christian. 2015. A Novel Steganography Technique for SDTV-H.264/AVC Encoded Video, Peru : School of Electrical Engineering, Peruvian University of Applied Sciences 